May $2002 \quad$ NREL/CP-520-31407

\title{
Terrestrial Solar Spectral Modeling Tools and Applications for Photovoltaic Devices
}

\section{Preprint}

D.R. Myers, and K.E. Emery

National Renewable Energy Laboratory

Dr. C. Gueymard

Consultant

To be presented at the $29^{\text {th }}$ IEEE PV Specialists Conference

New Orleans, Louisiana

May 20-24, 2002

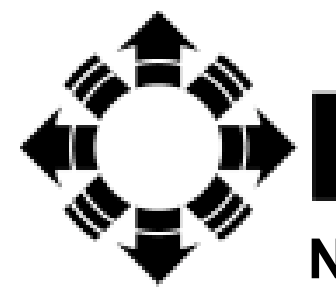

\section{NPEI}

National Renewable Energy Laboratory

1617 Cole Boulevard

Golden, Colorado 80401-3393

NREL is a U.S. Department of Energy Laboratory

Operated by Midwest Research Institute $\bullet$ Battelle $\bullet$ Bechtel

Contract No. DE-AC36-99-G010337 


\section{NOTICE}

The submitted manuscript has been offered by an employee of the Midwest Research Institute (MRI), a contractor of the US Government under Contract No. DE-AC36-99G010337. Accordingly, the US Government and MRI retain a nonexclusive royalty-free license to publish or reproduce the published form of this contribution, or allow others to do so, for US Government purposes.

This report was prepared as an account of work sponsored by an agency of the United States government. Neither the United States government nor any agency thereof, nor any of their employees, makes any warranty, express or implied, or assumes any legal liability or responsibility for the accuracy, completeness, or usefulness of any information, apparatus, product, or process disclosed, or represents that its use would not infringe privately owned rights. Reference herein to any specific commercial product, process, or service by trade name, trademark, manufacturer, or otherwise does not necessarily constitute or imply its endorsement, recommendation, or favoring by the United States government or any agency thereof. The views and opinions of authors expressed herein do not necessarily state or reflect those of the United States government or any agency thereof.

Available electronically at http://www.osti.gov/bridge

Available for a processing fee to U.S. Department of Energy and its contractors, in paper, from:

U.S. Department of Energy

Office of Scientific and Technical Information

P.O. Box 62

Oak Ridge, TN 37831-0062

phone: 865.576 .8401

fax: 865.576.5728

email: reports@adonis.osti.gov

Available for sale to the public, in paper, from:

U.S. Department of Commerce

National Technical Information Service

5285 Port Royal Road

Springfield, VA 22161

phone: 800.553 .6847

fax: 703.605.6900

email: orders@ntis.fedworld.gov

online ordering: http://www.ntis.gov/ordering.htm

Printed on paper containing at least $50 \%$ wastepaper, including $20 \%$ postconsumer waste 


\title{
TERRESTRIAL SOLAR SPECTRAL MODELING TOOLS AND APPLICATIONS FOR PHOTOVOLTAIC DEVICES
}

\author{
D.R. Myers, K. Emery, National Renewable Energy Laboratory, 1617 Cole Blvd, Golden, CO 80401 \\ Dr. C. Gueymard, Consultant, 174 Bluebird Lane, Bailey, CO.
}

\begin{abstract}
Variations in terrestrial spectral irradiance on photovoltaic devices can be an important consideration in photovoltaic device design and performance. This paper describes three available atmospheric transmission models, MODTRAN, SMARTS2, and SPCTRAL2. We describe the basics of their operation and performance, and applications in the photovoltaic community. Examples of model input and output data and comparisons between the model results for each under similar conditions are presented. The SMARTS2 model is shown to be much easier to use, as accurate as the complex MODTRAN model, and more accurate than the historical NREL SPCTRAL2 model.
\end{abstract}

\section{INTRODUCTION}

The atmosphere acts as a continuously variable filter affecting the solar radiation propagating to the ground. Atmospheric gases, aerosols and particles, water vapor and droplets (clouds), and various pollutants modify the distribution of solar energy with respect to wavelength. The result is a wide range of variation in the spectral distribution of natural sunlight. Spectral measurements in the field are expensive and labor intensive.

There are a wide variety of photovoltaic (PV) material combinations and systems with varying spectral response functions. The combination of the variability in natural spectral distributions and spectral response functions make designing, evaluating, and predicting the performance of $\mathrm{PV}$ devices in the real world challenging.

We briefly describe three models for generating spectral irradiance distributions for use in PV research, development, design, and deployment applications. We show the use of and issues associated with the models, and remark on their relevance to PV performance evaluation.

\section{THE ATMOSPHERE AND SPECTRAL MODELS}

Modeling radiative transfer through an absorbing, scattering, and emitting medium has a long history [1]. Research into physical and optical properties of the Earth's atmosphere and their effect on the propagation of solar radiation has resulted in the definition of standard atmospheres. These include the United States Standard Atmosphere (USSA) of 1966, revised in 1976 [2], and supplemental atmospheric models [3]. Similarly, a wide variety of radiative transfer models of differing complexity have evolved.

One means of computing radiative transfer is Monte-Carlo modeling. Interactions of individual photons with the physical properties of the media are modeled using random processes. For accuracy, a large number of photons and iterative computations are needed at each wavelength. The BRITE model of Blättner et al. [4] is an example.

Radiative transfer through an atmospheric path depends upon quantum properties of the atmospheric constituents. High-resolution models using these quantum properties are called line-by-line or LBL models [5-7]. An example is Fast Atmospheric Signature Code (FASCODE), developed by the Air Force Geophysical Laboratory (AFGL) [7]. These models are for narrow bandwidth regions and require significant computational resources and storage space. LBL models access databases, such as HITRAN [8], consisting of quantum parameters for many molecular species (more than one million spectral lines). LBL models are too complex and specialized for discussion here.

Less complex "band" models are simplified LBL models as described in [5]. Band models represent groups of absorption lines as transmittance functions of parameters such as absorber concentration, pressure, and absorption coefficients. MODTRAN (moderate resolution) and LOWTRAN (low resolution) developed by AFGL are popular, commercially available band models [9]. "Low" resolution corresponds to 20 wavenumbers $(0.2 \mathrm{~nm}$ at 300 $\mathrm{nm}$ to $32 \mathrm{~nm}$ at $4000 \mathrm{~nm}$ ), and "moderate" resolution corresponds to two wavenumbers $(0.02 \mathrm{~nm}$ at $300 \mathrm{~nm}$ to $3 \mathrm{~nm}$ at $4000 \mathrm{~nm}$ ).

These models can address complex scenarios, including clouds, fog, smoke, many choices of standard and user defined aerosol properties, atmospheric structure for up to 33 different layers, and extraterrestrial spectra. They are designed to compute atmospheric transmittance between two points on or above the Earth's surface. The many combinations of input parameters and their interaction require a great deal of understanding by the user. Interpretation of the results is daunting, as well.

Simpler models are based on parameterizations of transmittance and absorption functions for basic atmospheric constituents. These usually are molecular, Rayliegh, ozone, water vapor, and aerosol transmittances. An extraterrestrial spectrum is modified by the product of 
transmittance coefficients or functions, and the path length and geometry to produce the transmitted solar spectral distribution. Their spectral resolution is generally lower (on the order of nanometers) than that of complex models.

SPCTRAL2, the simple spectral model of Bird [10], SEDES2 (derived from SPCTRAL2) [11], and the Simple Model for Atmospheric Transmission of Sunshine (SMARTS2) of Gueymard [12] represent this approach, after Leckner [13]. These models require few input parameters. They are useful for engineering applications requiring less accuracy and resolution than complex models. In the next section, we compare and contrast the use of MODTRAN, SPCTRAL2, and SMARTS2 for PV applications. SEDES2 is a modified version of SPCTRAL2 where cloud cover and measured broadband global irradiance is used to modify the clear sky SPCTRAL2 model for use under cloudy skies.

\section{MODELING STANDARD SPECTRA}

Standard reporting conditions for PV device performance specify the standard reference spectra, American Society for Testing and Materials (ASTM) G159-98 [14]. These spectra are also used by the International Electrotechnical Commission (IEC) [15] and the International Standards Organization (ISO) [16]. The spectra were developed in 1982 and revised in 1987. They are based on the work of Bird, Hulstrom, and Lewis [17]. The spectra were computed using the BRITE MonteCarlo model for 122 individual wavelengths from $305 \mathrm{~nm}$ to $2500 \mathrm{~nm}$. An undocumented simple model was used to extend the spectra to $4045 \mathrm{~nm}$. It is not possible to reproduce these spectra, as BRITE code was specific to the (now obsolete) mainframe computer used.

BRITE was used to develop and validate Bird's empirical SPCTRAL2 model. Both models used 1975 aerosol profiles of Shettle and Fenn [18]. Here we show differences between the present direct normal spectral irradiance distribution and model results from SPCTRAL2, SMARTS2 version 2.9, and MODTRAN version 4 . SPCTRAL2 inputs shown in Table 1 produce an approximation to the G159-98 direct normal spectrum.

Table 1. SPCTRAL2 parameters to approximate ASTM G159-98 Direct Normal Reference Spectrum.

\begin{tabular}{lc}
\hline \multicolumn{1}{c}{ Parameter } & Value, Units \\
\hline Aerosol Optical Depth 500nm & 0.27 \\
Angstrom Wavelength Exponent & 1.14 \\
Fixed Ground Albedo & 0.2 \\
Equivalent Depth Ozone & $0.34 \mathrm{~cm}$ \\
Equivalent Depth Water Vapor & $1.42 \mathrm{~cm}$ \\
Scattering Asymmetry Factor & 0.65 \\
Angle of Incidence & $11^{\circ}$ \\
Atmospheric Pressure & $1013.25 \mathrm{mB}$ \\
Zenith Angle of Sun & $48.19^{\circ}$ \\
(Equivalent to Air Mass 1.5) & 51 \\
Day of Year & $12 \mathrm{H}$ \\
Hour & $03 \mathrm{Min}$ \\
Minute & $40^{\circ} \mathrm{N}$ \\
Latitude & $105^{\circ} \mathrm{W}$ \\
Longitude &
\end{tabular}

Fixed parameters in the model include the single scattering albedo (0.945), single scattering albedo humidity factor (0.095), aerosol asymmetry factor (0.65), and Ångstrom exponent (1.14).

SPCTRAL2 computes the spectral irradiance at irregularly spaced wavelengths, not identical to those in the G159-98 reference. Since BRITE and SPCTRAL2 are different models, SPCTRAL2 does not exactly reproduce the reference spectrum but only an approximation of it. Deviations from the reference direct spectrum are actually large in water vapor absorption bands (see Fig. 2).

Inputs for SMARTS2 to approximate the direct reference spectrum are shown in Table 2. SMARTS2 is based on parameterizations of MODTRAN transmission functions, and results compare with MODTRAN spectral results to with $\pm 2 \%$ [12] .

SMARTS2 version 2.9 permits the selection of 10 default atmospheric profiles or a user-specified profile; 8 default aerosol optical depth profiles or a user-specified profile; 36 spectral albedo files or a user-defined albedo file; and 6 concentration levels (including user-defined concentration of any or all) of 10 pollutant gases such as nitrous oxide and carbon monoxide. A "card deck" of no more than 30 lines specifies the scenario conditions.

Table 2. SMARTS2 parameters to approximate ASTM G159-98 Direct Normal Reference Spectrum.

\begin{tabular}{ll}
\hline SMARTS2 Parameter & Value \\
\hline Pressure mode $(1=$ pressure and altitude) & 1 \\
Station pressure $(\mathrm{mb})$ \& altitude $(\mathrm{km})$ & $1013.25,0.0$ \\
Use a default atmosphere & 1 \\
Default standard atmosphere profile & 'USSA' \\
Default water vapor from profile & 1 \\
Default ozone from profile & 1 \\
No pollution modifications (default to profile) & 1 \\
Carbon monoxide volume mixing ratio (ppmv) & 330 \\
Gueymard extraterrestrial spectrum & 1 \\
Aerosol profile to use & 'S\&F_RURA \\
Aerosol mode: optical depth at 500 nm & $\mathrm{L}$ \\
Aerosol optical depth @ 500 nm & 0 \\
Spectral albedo file: light sandy soil & 0.27 \\
Specify tilt calculation & 38 \\
Albedo file, tilt, azimuth & 1 \\
Start, stop nm, radius vector, solar constant & $38,37,180$ \\
Spectral output file print mode (spreadsheet) & 280,4000, \\
Print limits, start, stop, minimum step size nm & 2 \\
Number of output variables to print & 280,4000, \\
Output 8 = hemispherical tilt; & 0.5 \\
9 = direct normal + circumsolar & 2 \\
Circumsolar calculation mode & 8,9 \\
Receiver slope, view, limit half angles & 1 \\
Smooth function mode $(0=$ none $)$ & $0,2.9,0$ \\
Illuminance calculation mode $(0=$ none) & 0 \\
UV calculation mode $(0=$ none $)$ & 0 \\
Solar geometry mode $(2=$ Air Mass $)$ & 0 \\
Air mass value & 2 \\
\hline & 1.5 \\
\hline
\end{tabular}


MODTRAN can be obtained directly from the AFGL, or with a windows user interface from Ontar Corp, Andover, MA. To approximate the reference direct normal spectrum with MODTRAN, version 4 we used the Ontar MODTRAN4 software with USSA 1976 atmospheric profile and the parameters indicated in table 3 for the first four input screens. Broken lines in table 3 indicate divisions between input screens. Figure 1 is an image of the fifth MODTRAN4 input screen describing the geometry and wavelength parameters for the model.

MODTRAN4 generates a verbose output file (MODOUT1) and a terse spreadsheet compatible output file (MODOUT2), each is $3.0 \mathrm{MB}$ to $3.5 \mathrm{MB}$ in size. All computational results for every atmospheric layer and wavelength are saved in the verbose output. Only frequency (wavenumber) and radiance or irradiance data are saved in the terse file. The user must convert wavelength units from wavenumber to other units if desired.

Table 3. First four input "cards" (separated by dashed lines) to approximate ASTM G159-98 Direct Normal Reference Spectrum for Ontar MODTRAN4.

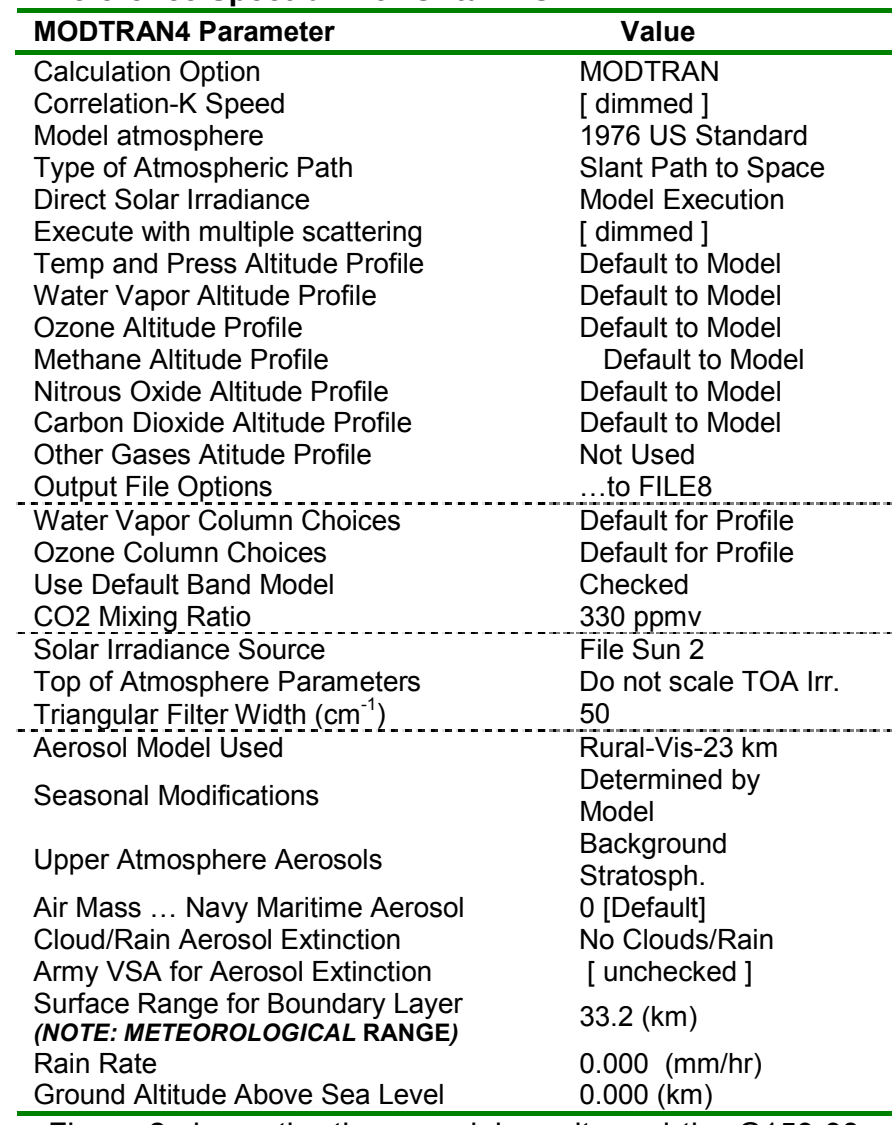

Figure 2 shows the three model results and the G159-98 direct normal spectrum between $300 \mathrm{~nm}$ and $1100 \mathrm{~nm}$.

MODTRAN4 requires a meteorological range of $33.2 \mathrm{~km}$, equivalent to a visual range of $25.5 \mathrm{~km}$ to approximate the reference direct spectrum. This is equivalent to an aerosol optical depth of 0.34 , using current aerosol models. If a meteorological range of $23 \mathrm{~km}$ (equivalent to visual range of $21.5 \mathrm{~km}$ ) is used, MODTRAN reports an aerosol optical depth of 0.27 , as for the reference spectra. It is possible that in the original reference spectra computations the meteorological range and visual range values were reversed.

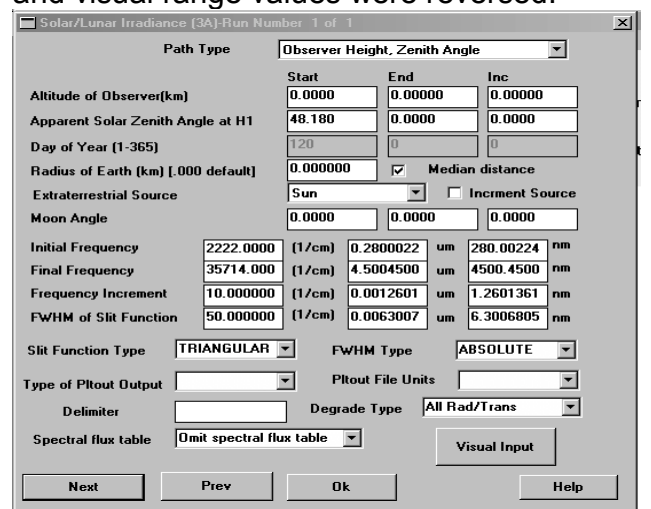

Fig. 1. Input screen 5 for Ontar MODTRAN4, user interface, specifying geometry and wavelength regime for scenario.

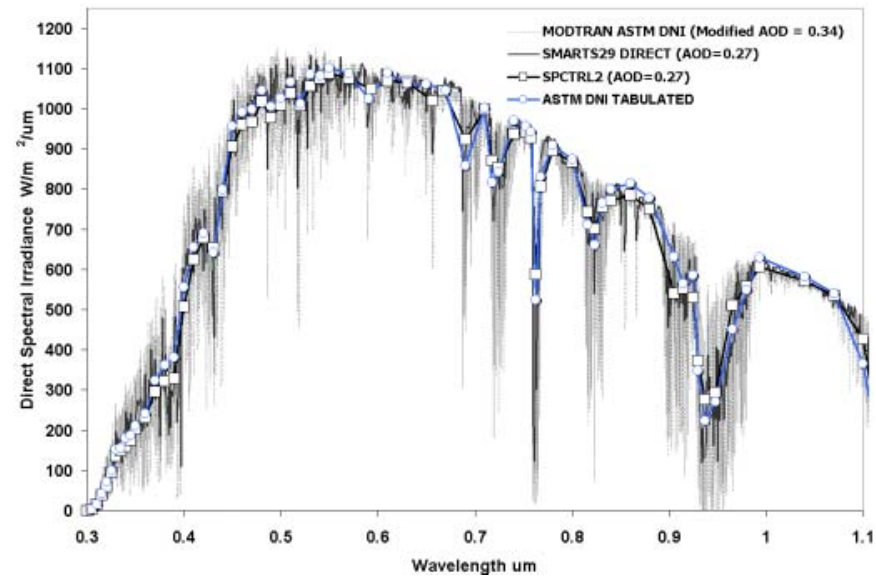

Fig. 2. Model approximations to the ASTM direct normal spectrum resulting from parameters in tables 1-3. Stipple gray line is MODTRAN4, black line is SMARTS2, squares mark SPCTRAL2, and circles mark the direct normal reference tabular data.

\section{PARAMETRIC STUDIES}

These models may be used to study the effects of various atmospheric conditions on terrestrial spectral irradiance. Figure 3 shows SMARTS2 direct normal irradiance for identical conditions at $0 \mathrm{~km}$ and $5 \mathrm{~km}$. Figure 4 compares SMARTS2 direct normal spectra under "light" and "heavy" pollution conditions. SMARTS2 and MODTRAN allow pollutant concentrations to be varied by the user.

Similar studies using SPCTRAL2 could be approximated by manipulating aerosol optical depth alone, but spectral changes may not occur in the correct spectral regions. Spectral mismatch computations are straightforward and much easier with the 1-nm step size and resolution of SMARTS2. Comparison with measured 
data can be done using MODTRAN or SMARTS2 by using smoothing functions with passbands to match the passband of instrumentation.

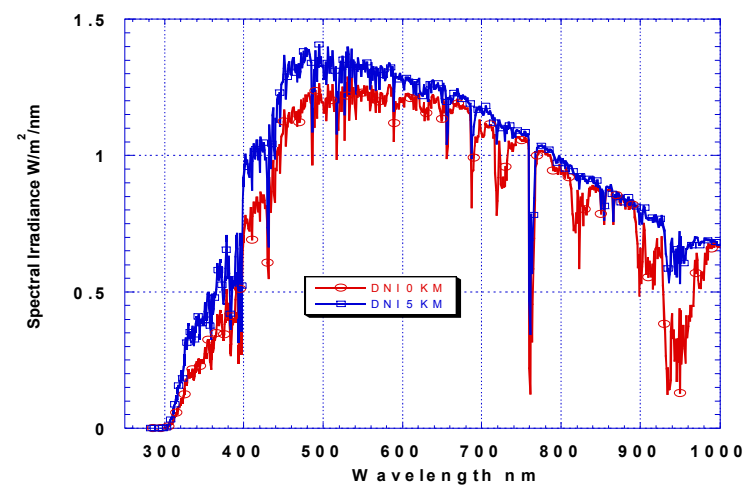

Fig. 3. SMARTS2 Direct normal spectra at sea level (lower curve) and $5 \mathrm{~km}$ elevation (higher curve). Air mass=1.5, aerosol optical depth $=0.15$, water vapor $=1.42 \mathrm{~cm}$, ozone $=0.34$ cm, Shettle and Fenn Rural Aerosol Profile, USSA 1976 atmosphere, default profile-no pollution.

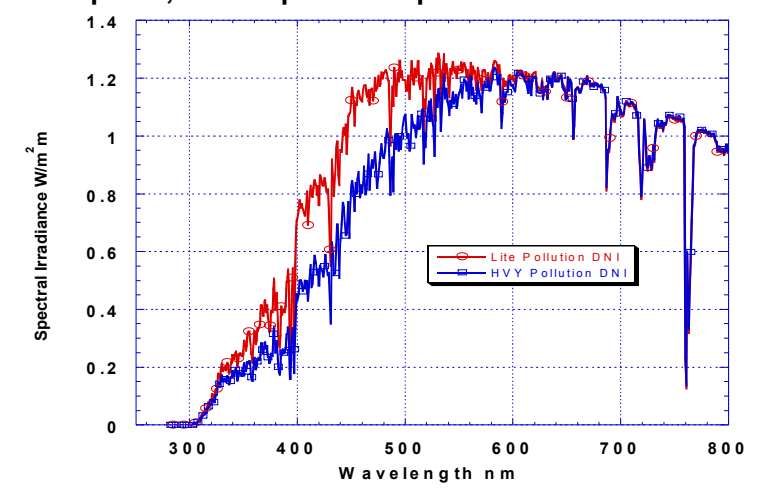

Fig. 4. SMARTS2 direct normal spectra for light (top curve) and heavy pollutant concentrations with conditions as in figure 3 at sea level.

\section{CONCLUSIONS}

MODTRAN is complex to use and is not suitable to compute hemispherical total spectral irradiance. SPCTRAL2 lacks flexibility to model the effects of atmospheric constituents and is less accurate than SMARTS2 when compared with MODTRAN. SMARTS2 requires fewer than 30 input parameters and its results are within $2 \%$ of MODTRAN4. SMARTS2 can address diverse albedo and atmospheric constituent scenarios. SMARTS2 is available for both IBM and Macintosh platforms. Government entities may obtain MODTRAN source code from the AFGL. MODTRAN4 with a windows user interface is available from ONTAR Corporation, 9 Village Way, Andover MA 01845. SPCTRAL2 and SMARTS2 are in the public domain and available from the authors.

\section{ACKNOWLEDGMENTS}

This paper is dedicated to the memory of Dr. Richard E. Bird, who passed away 18 April 2002. His contributions have served the PV community immeasurably over the past 15 years. This work was performed at NREL under U.S. Department of Energy prime contract \#DE AC36 99GO10337.

\section{REFERENCES}

[1] Chandreskar S., Radiative Transfer, Dover Publications Inc., New York, 1960.

[2] Anon.. U.S. Standard Atmosphere, 1976

http://nssdc.gsfc.nasa.gov/space/model/atmos/us_standard.html. Washington, DC, NOAA/NASA/USAF (1976).

[3] Champion, K.S.A., et al.. "Standard and Reference Atmospheres."Handbook of Geophysics and the Space Environment. A. S. Jursa, ed. Air Force Geophysics Laboratory (1985).

[4] Blättner, W.G., et al. (1974). "Monte Carlo Studies of the Sky Radiation at Twilight." Appl. Opt. 13: 534-537.

[5] Fenn, R.W., et al., "Optical and Infrared Properties of the Atmosphere". Handbook of Geophysics and the Space Environment, A.S. Jursa, Air Force Geophysics Laboratory, 181:18-80 (1985).

[6] Scot, N.A.,. and A. Chedin, "A Fast line by Line Method for Atmospheric Absorption Computations: The Automatized Absorption Atlas" J. Appl. Meteor. 20:802-812.

[7] Anderson, G.P., et al. "Reviewing Atmospheric Radiative Transfer Modeling: New Developments in High and Moderate Resolution FASCODE/FASE and MODTRAN". Optical Spectroscopic Techniques and Instrumentation for Atmospheric and Space Research II, Society of Photo-Optical Instrumentation Engineers.SPIE 2830 (1996).

[8] Rothman, L.S., et al. "The HITRAN molecular database: Editions of 1991 and 1992." J. Quant. Spectros. Rad. Trans. 48: 469-507, (1992).

[9] Anderson,G.P., et al. "History of One Family of Atmospheric Radiative Transfer Codes". Passive Infrared Remote Sensing of Clouds and the Atmosphere II, Society of Photo-optical Instrumentation Engineers. SPIE 2309 (1994).

[10] Bird, R.E., and C. Riordan, "Simple Solar Spectral Model for Direct and Diffuse Irradiance on Horizontal and Tilted Planes at the Earth's Surface for Cloudless Atmospheres", J. Clim. \& App. Meteor. 25, pp. 87-97 (1986).

[11] Nann, S. and C. Riordan, "Solar Spectral Irradiance under Clear and Cloudy Skies: Measurements and an Empirical Model" Jour. Appl. Metero. Vol 30 No. 4 (1991).

[12] Gueymard, C., "Parameterized Transmittance Model for Direct Beam and Circumsolar Spectral Irradiance." Solar Energy 71(5): 325-346.(2001).

[13] Leckner, B.,"The spectral distribution of solar radiation at the Earth's surface-Elements of a model." Solar Energy 20: 143150.(1978).

[14] ASTM Standard Tables for Reference Solar Spectral Irradiance at Air Mass 1.5: Direct Normal and Hemispherical for a $37^{\circ}$ Tilted Surface, Standard G159-99, American Society for Testing and Materials, West Conshohocken, PA. 1999.

[15] IEC Photovoltaic Devices: Part 3: Measurement principles for terrestrial photovoltaic (PV) solar devices with reference spectral irradiance data. IEC 904-3, International Electro Technical Commission.(1989).

[16] ISO Solar Energy-Reference solar spectral irradiance at the ground at different receiving conditions, pt. 1, International Organization for Standardization, Geneva.(1992).

[17] Bird, R.E., et al. "Terrestrial solar spectral data sets." Solar Energy 30(6): 563-573. (1983).

[18] Shettle, E.P., and R. W. Fenn. "Models of the Atmospheric Aerosols and their Optical Properties", Electromagnetic Wave Propagation Panel Symposium, Lyngby, Denmark, 27-31 October, 1975. 


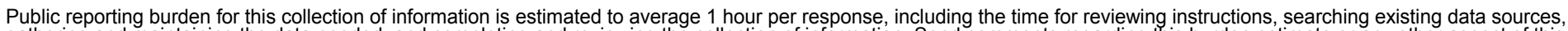

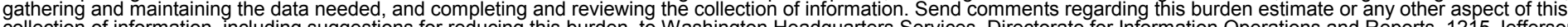
Davis Highway, Suite 1204, Arlington, VA 22202-4302, and to the Office of Management and Budget, Paperwork Reduction Project (0704-0188), Washington, DC 20503.

\begin{tabular}{|c|c|c|}
\hline 1. AGENCY USE ONLY (Leave blank) & $\begin{array}{l}\text { 2. REPORT DATE } \\
\text { May } 2002\end{array}$ & $\begin{array}{l}\text { 3. REPORT TYPE AND DATES COVERED } \\
29^{\text {th }} \text { IEEE PVSC-Conference Paper } \\
\text { May } 20-242002\end{array}$ \\
\hline
\end{tabular}

4. TITLE AND SUBTITLE

Terrestrial Solar Spectral Modeling Tools and Applications for Photovoltaic Devices:

Preprint

6. $\operatorname{AUTHOR}(\mathrm{S})$
D.R. Myers, ${ }^{1}$ K.E. Emery, ${ }^{1}$ and Dr. C. Gueymard ${ }^{2}$

7. PERFORMING ORGANIZATION NAME(S) AND ADDRESS(ES)

1. National Renewable Energy Laboratory, 1617 Cole Blvd, Golden, CO 80401

2. Consultant, 174 Bluebird Lane, Bailey, CO

9. SPONSORING/MONITORING AGENCY NAME(S) AND ADDRESS(ES)

National Renewable Energy Laboratory

1617 Cole Blvd.

Golden, CO 80401-3393
5. FUNDING NUMBERS PVP27401

8. PERFORMING ORGANIZATION REPORT NUMBER

10. SPONSORING/MONITORING AGENCY REPORT NUMBER

NREL/CP-520-31407

11. SUPPLEMENTARY NOTES

12a. DISTRIBUTION/AVAILABILITY STATEMENT National Technical Information Service

U.S. Department of Commerce

5285 Port Royal Road

Springfield, VA 22161

12b. DISTRIBUTION CODE

13. ABSTRACT (Maximum 200 words): This conference paper describes the variations in terrestrial spectral irradiance on photovoltaic devices can be an important consideration in photovoltaic device design and performance. This paper describes three available atmospheric transmission models, MODTRAN, SMARTS2, and SPCTRAL2. We describe the basics of their operation and performance, and applications in the photovoltaic community. Examples of model input and output data and comparisons between the model results for each under similar conditions are presented. The SMARTS2 model is shown to be much easier to use, as accurate as the complex MODTRAN model, and more accurate than the historical NREL SPCTRAL2 model.

14. SUBJECT TERMS: PV; terrestrial spectral irradiance; spectral measurements; Monte-Carlo model; fast atmospheric signature code (FASCODE); broadband global irradiance; direct normal reference spectrum; solar radiation; scattering asymmetry factor;

15. NUMBER OF PAGES

16. PRICE CODE

17. SECURITY CLASSIFICATION OF REPORT Unclassified

\author{
18. SECURITY CLASSIFICATION \\ OF THIS PAGE \\ Unclassified
}

19. SECURITY CLASSIFICATION OF ABSTRACT Unclassified
20. LIMITATION OF ABSTRACT

UL 